\title{
Analysis of Hybrid Nanofluid Stagnation Point Flow over a Stretching Surface with Melting Heat Transfer
}

\author{
Muhammad Jawad $\mathbb{D}^{1}{ }^{1}$ Ziad Khan $\mathbb{D}^{1},{ }^{1}$ Ebenezer Bonyah $\mathbb{D}^{2},{ }^{2}$ and Rashid Jan ${ }^{1}{ }^{1}$ \\ ${ }^{1}$ Department of Mathematics, University of Swabi, Swabi 23561, Khyber Pakhtunkhwa, Pakistan \\ ${ }^{2}$ Department of Mathematics Education, Akenten Appiah Menka University of Skills Training and Entrepreneurial Development, \\ Kumasi, Ghana \\ Correspondence should be addressed to Ebenezer Bonyah; ebbonya@gmail.com
}

Received 26 October 2021; Revised 31 December 2021; Accepted 8 January 2022; Published 3 February 2022

Academic Editor: Arshad Riaz

Copyright (c) 2022 Muhammad Jawad et al. This is an open access article distributed under the Creative Commons Attribution License, which permits unrestricted use, distribution, and reproduction in any medium, provided the original work is properly cited.

\begin{abstract}
The behavior of hybrid nanofluid and stagnation point flow toward a stretched surface along with melting heat transfer, secondorder slip, electric field, and magnetic field effect is investigated in this study. Hybrid nanoparticles alumina $\left(\mathrm{Al}_{2} \mathrm{O}_{3}\right)$ and copper $(\mathrm{Cu})$ are considered with the base fluids water $\left(\mathrm{H}_{2} \mathrm{O}\right)$. The PDEs with corresponding boundary constraints are transformed into a set of nonlinear ODEs using similarities transformation. The set of nonlinear ODEs are analyzed analytically using semianalytical method HAM in Mathematica software. Dual solution is determined which relaying on the emerging parameters included magnetic field, volume fractions, electric field, dimensionless surface velocity slip factors, Eckert number, and Prandtl number. The results are shown in the velocity and temperature curves as well as skin friction coefficient and local Nusselt number. The analysis shows that velocity profile is an increasing function of slip parameter, electric field, while reducing function of magnetic field. Temperature profile is an increasing function of magnetic field parameter, electric field parameter, volume fraction parameter, and Eckert number, while reducing function of Prandtl number. The main outcomes are as follows that hybrid nanofluids are higher thermal properties as compared to conventional fluids. As a result, hybrid nanofluid has numerous uses in engineering cosmetics, automotive industry, home industry, for cancer treatment, food packaging, pharmaceuticals, fabrics, paper plastics, paints, ceramics, food colorants, and soaps as well.
\end{abstract}

\section{Introduction}

A conventional fluid like ethylene glycol and water has less value of thermal conductivity. Additions of nanosized particle improved thermal characteristics of ordinary fluids. Due to its exceptional thermophysical characteristic, a new class of fluids known as hybrid nanofluid is being used in a wide range of technical application. Hybrid nanofluids are advanced types of nanofluids that are made up of two distinct nanoparticles mixed together with a base fluid. Due to its thermal properties, hybrid nanofluids have become a new dawn for the young researcher and academics who have begun to explore hybrid nanofluids in solar energy. Mathematical modeling and its analysis contributed a lot to inspect natural phenomena in different fields of research [1-5].
The literature of heat absorption or generation of hybrid nanoparticles is rich, and many researchers contributed to study this phenomenon. Verma et al. [6] compute energy and energy efficiencies in flat plate solar collectors employing copper oxides $(\mathrm{CuO}) / \mathrm{MWCNTs}$ (multiwall carbon nanotubes) and magnesium oxides ( $\mathrm{MgO}) /$ MWCNTs nanofluid. Chen et al. [7] investigated the use of $\mathrm{CuO} / \mathrm{ATO}$ (antimony-doped tin oxide) hybrid nanofluid in solar energy applications. The properties of MWCNTs-Ag/ $\mathrm{SiO}_{2}$ hybrid nanofluid in solar energy industry are investigated by Zeng et al. [8]. The authors selected these combinations due to greater absorption radiations of MWCNTs (multiwall carbon nanotubes). It is shown that multiwall carbon nanotubes (MWCNTs) are more efficient as compared to $\mathrm{Ag} / \mathrm{SiO}_{2}$. Xuan et al. [9] investigate the effect of 
concentration on temperature using plasmonic hybrid nanofluid, namely, $\mathrm{TiO}_{2}-\mathrm{Ag} /$ water in a solar energy absorption. The addition of nanoparticles to the refrigerant improved heat transmission and resulted in a high heat transfer coefficient for refrigeration systems. Viscosity and thermal conductivity are essential aspects to find out the performance of nanorefrigerants against ordinary water fluids. To test refrigeration system's performance, the researchers utilized different nanorefrigerants instead of traditional fluids. The efficiency of heating, ventilation, and air conditioning (HVAC) systems in refrigerant is improved by using nanoparticles. Different techniques are utilized for this motivation like ultrasonic agitation and magnetic force agitation. Experimental tests are performed by Bi et al. [10] to determine boiling heat transfer characteristics of R22 refrigerants along $\mathrm{Al}_{2} \mathrm{O}_{3}$ nanoparticle. According to findings, the inclusion of nanoparticles enhanced refrigerant heat transmission while reducing the size of bubbles that move rapidly along heat transfer surface. Ahmed and Elsaid [11] investigate characteristics of vapor compression refrigeration with chilled water air conditioning. The purpose of heat exchangers is to transfer heat from hot fluids to cool fluids, and the use of nanofluids in heat exchangers is a recent development. According to researchers and scientists, the thermal performance of heat exchangers may be considerably improved by improving thermal conductivity of base fluids. As a result, different fluids like nanofluids and hybrid nanofluids improve heat exchangers' thermal performance. Through the use of tabular heat exchanger, Madhesh and Kalaiselvam [12] studied heat transfer enhancement and rheological behavior of hybrid nanofluid. Allahyar et al. [13] performed tests using alumina-silver hybrid nanofluid to measure characteristics and pressure decrease in helical coil heat exchangers. The thermal managements of an automobile's engine are essential since it has a direct impact on its efficiency in terms of economy, materials selections, and pollution control. The addition of nanoparticles to engine oil increases vehicle performance as well as engine cooling.

Ali et al. [14] used alumina- $\mathrm{TiO}_{2}$ /oil hybrid nanofluid to investigate frictional power losses and wear rate in sliding contacts between piston ring and cylinder. By aggregating all research of a particular type of nanofluid, Sidik et al. [15] evaluated a study on motor oil cooling systems. Nanosize particle which is also cheap in cost and widely accessible may be employed in mineral oil, which increases dielectric characteristics of transformers and oil-based electrical components. Choi et al. [16] utilized $\mathrm{Al}_{2} \mathrm{O}_{3} / \mathrm{AIN}$ transformer oil-based nanofluid to improve thermal characteristic of oils. The use of nanoparticles in water-cooled nuclear reactors has potential to significantly enhance system performance in terms of economic costs and safety margins. The heat flux in fuel rod plays critical roles in determining the performance of nuclear reactors because of maximal heat flow. Boungiorno and $\mathrm{Hu}$ [17] observed nanofluids' essential heat flow and improved heat transfer in nuclear reactors. Mousavizadeh et al. [18] explore $\mathrm{TiO}_{2}$ /water nanofluid for evaluating heat transfer properties of the VVER-1000 nuclear reactors.

Nanotechnology used at cellular and molecular level has resulted in significant advancements in health care and life sciences [19]. In biomedical field, nanofluids and nanoparticles are frequently utilized. Nanoparticles adhere to tumor cells better than normal cells, and combining impact of radiation and hypothermia is related to heat created during the repair process as a result of radiation-induced DNA damage [20]. The primary goal of biomedical nanotechnology development is to efficiently monitor and regulate biological cell activity. Kleinstreuer et al. [21] developed biomicroelectronics mechanical systems for the first time. Nanofluids are now finding use in cancer imaging and medication administration because of their unique characteristics of nanoparticles. Iron-based nanoparticles and magnetic nanofluid are used for guiding tumors through magnet. As a consequence, cancer therapy can be improved and afflicted portions can be diagnosed without causing damage to healthy tissues. In comparison with other metal nanoparticles, magnetic nanoparticles are frequently utilized because they may be controlled by magnetic force [22]. Yan and Liu [23] conducted simulation on phase change bioheat transfer at cell levels to compare the temperatures of traditional cryosurgery with nanocryosurgery. Using $\mathrm{Al}_{2} \mathrm{O}_{3}$ /water nanoparticle, Mansoury et al. [24] investigate the performance of parallel flow heat exchanger. The stagnation point flow in hybrid nanofluid across a shrinking cylinder along slip impact and viscous dissipation was researched by Ghazali et al. [25]. Alghamdi et al. [26] investigate hybrid nanofluid MHD flow containing the medicine through blood vessels. The movement of nanomaterial between two stretchy disks was investigated by Ijaz Khan and Alzahrani [27]. Gul et al. [28] studied hybrid nanoparticle flow in the conical gap between the cone and the surface of a spinning disk. Ghadikolaei et al. [29] investigate the thermophysical characteristics of $\mathrm{TiO}_{2}-\mathrm{Cu} / \mathrm{H}_{2} \mathrm{O}$ hybrid nanoliquid using Lorentz force. The problems of heat transfer of aluminum oxide and copper hybrid nanoparticles are numerically studied by Tayebi and Chamkha [30]. Besides, Waini et al. [31] consider hybrid nanofluid flow and heat transfer over a permeable biaxial stretching/shrinking sheet. Moreover, the problems of a hybrid nanofluid flow with the influence of various emerging parameters are also considered by many researchers [32-36].

The aim of the present study is to investigate a steady two-dimensional boundary layer MHD hybrid nanofluid and stagnation point flow toward a stretching surface with melting heat transfer and second-order slip. Here, $\mathrm{Al}_{2} \mathrm{O}_{3}$ and $\mathrm{Cu}$ are considered as the hybrid nanofluid while $\mathrm{H}_{2} \mathrm{O}$ as the base fluid. It is well known that it has numerous uses in engineering cosmetics, automotive industry, home industry, for cancer treatment, food packaging, pharmaceuticals, fabrics, paper plastics, paints, ceramics, food colorants, and soaps as well. Also, the comparison between HAM and NDSolve solution is computed for $f(\eta), f^{\prime}(\eta)$ and $\theta(\eta)$. 


\section{Mathematical Modeling}

Here, we assume a steady two-dimensional boundary layer MHD hybrid nanofluid and stagnation point flow with melting heat transfer and second-order slip toward a stretching surface. The surface velocities and external flow of the stretching surface are, respectively, defined as $u_{w}(x)=\gamma x, u_{e}(x)=\omega x$ $(x)=\omega x$, where $\omega$ and $\gamma$ are constants. The melting surface and ambient temperature are, respectively, represented by $T_{m}$ and $T_{\infty}$, where $T_{m}<T_{\infty}$. The governing equations and boundary conditions can be written in the following way (see Waini et al. [37] and Walelign et al. [38]):

$$
\begin{aligned}
\frac{\partial u}{\partial x}+\frac{\partial v}{\partial y}= & 0, \\
u \frac{\partial u}{\partial x}+v \frac{\partial u}{\partial y}= & u_{e} \frac{d u_{e}}{d x}+\frac{\mu_{h n f}}{\rho_{h n f}} \frac{\partial^{2} u}{\partial y^{2}} \\
& +\frac{\sigma_{h n f}}{\rho_{h n f}}\left(E_{0} B_{0}-B_{0}^{2}\left(u_{e}-u\right)\right), \\
u \frac{\partial T}{\partial x}+v \frac{\partial T}{\partial y}= & \frac{k_{h n f}}{\left(\rho C_{p}\right)_{h n f}} \frac{\partial^{2} T}{\partial y^{2}}+\frac{\sigma_{h n f}}{\left(\rho C_{p}\right)_{h n f}} \\
& \left(u B_{0}-E_{0}\right)^{2}+\frac{Q_{0}}{\left(\rho C_{p}\right)_{h n f}}\left(T-T_{\infty}\right), \\
u= & u_{w}(x)+u_{s l i p}, \\
T= & T_{m} \\
a t y & =0 ; \\
u & \longrightarrow u_{e}(x), \\
T & \longrightarrow T_{\infty} \\
a s y & \longrightarrow \infty, \\
k_{h n f}\left(\frac{\partial T}{\partial y}\right)_{y=0} & \rho_{h n f}\left[L+c_{s}\left(T_{m}-T_{0}\right)\right] v(x, 0) .
\end{aligned}
$$

Here, $u$ and $v$ represent the velocity term in the direction of $x$ - and $y$-axes, respectively, and the temperature and latent heat of the hybrid nanofluid are indicated by $T$ and $L$. Equation (5) shows the melting surface condition which is introduced by Roberts [39] in which $c_{s}$ denotes heat capacity. Further, dynamic viscosity, thermal conductivity, heat capacity, and density of the hybrid nanofluid are represented, respectively, by $\mu_{h n f}, k_{h n f},\left(\rho C_{p}\right)_{h n f}$, and $\rho_{h n f}$.

Moreover, the slip velocity $u_{\text {slip }}$ is introduced by [40] and defined as

$$
u_{\text {slip }}=A \frac{\partial u}{\partial y}+B \frac{\partial^{2} u}{\partial y^{2}} .
$$

The similarity transformation of this study is defined as follows:

$$
\begin{gathered}
u=\omega x f^{\prime}(\eta), \\
v=-\left(\omega v_{f}\right)^{1 / 2} f(\eta), \\
\theta(\eta)=\frac{T-T_{m}}{T_{\infty}-T_{m}} \\
\eta=y\left(\frac{\omega}{v_{f}}\right)^{1 / 2} .
\end{gathered}
$$

Using equation (7) into equations (2)-(4), we get a set of nonlinear ODEs:

$$
\begin{aligned}
& \frac{\mu_{h n f}}{\mu_{f}} f^{\prime \prime \prime}+f f^{\prime \prime}-f^{\prime 2}+1+\frac{\sigma_{h n f} / \sigma_{f}}{\rho_{h n f} / \rho_{f}} M\left(E-\left(1-f^{\prime}\right)\right)=0, \\
& \frac{1}{\operatorname{Pr}} \frac{k_{h n f} / k_{f}}{\left(\rho C_{p}\right)_{h n f} /\left(\rho C_{p}\right)_{f}} \theta^{\prime}+f \theta^{\prime}+\frac{\sigma_{h n f} / \sigma_{f}}{\left(\rho C_{p}\right)_{h n f} / \rho_{f}} M E c\left(f^{\prime}-E\right) \\
& \quad+\frac{\left(\rho C_{p}\right)_{f}}{\left(\rho C_{p}\right)_{h n f}} \mathrm{Q} \theta=0 .
\end{aligned}
$$

Dimensionless form of boundary conditions is as follows:

$$
\begin{array}{r}
\operatorname{Pr} \frac{\rho_{h n f}}{\rho_{f}} f(0)+M_{1} \frac{k_{h n f}}{k_{f}} \theta^{\prime}(0)=0, \\
f(0)=\lambda+\alpha f^{\prime \prime}(0)+\beta f^{\prime}(0), \theta(0)=0, \\
f^{\prime}(\eta) \longrightarrow 1, \theta(\eta) \longrightarrow 1, \text { as } \eta \longrightarrow \infty .
\end{array}
$$

Here, prime represents differentiation in terms of $\eta, v_{f}$ is kinematic viscosity of the fluid, $\operatorname{Pr}$ is Prandtl number, $\lambda$ is stretching parameter, $0 \leq \alpha$ (first order) and $0 \geq \beta$ (second order) are the dimensionless velocity slip parameters, $M_{1}$ is melting parameter, $E$ is electric parameter, $M$ is magnetic parameter, and $E c$ is Eckert number, which is determined as follows:

$$
\begin{aligned}
& \lambda=\frac{\gamma}{\omega}, \\
& \operatorname{Pr}=\frac{\left(\mu C_{p}\right)_{f}}{k_{f}}, \\
& \alpha=A \sqrt{\frac{\omega}{v_{f}}}, \\
& \beta=\frac{\omega B}{v_{f}},
\end{aligned}
$$




$$
\begin{aligned}
M_{1} & =\frac{\left(T_{\infty}-T_{m}\right)\left(C_{p}\right)_{f}}{L+\left(T_{m}-T_{0}\right) c_{s}}, \\
E & =\frac{E_{0}}{\beta_{0} \omega x}, \\
M & =\frac{\sigma \beta_{0}^{2}}{\rho_{f} \omega}, \\
E c & =\frac{\omega x^{2}}{C_{p} \Delta T} .
\end{aligned}
$$

\section{Physical Quantities}

Here, the subscripts $h n f, n f$, and $f$ indicate hybrid nanofluids, nanofluids, and fluids, respectively, while the volume fraction of nanoparticles $\left(\mathrm{Al}_{2} \mathrm{O}_{3}\right)$ and $(\mathrm{Cu})$ are denoted by $\phi_{1}$ and $\phi_{2}$ and there solid components are represented by $n_{1}$ and $n_{2}$. The skin friction coefficient $\left(C_{f}\right)$ and the local Nusselt number $\left(N u_{x}\right)$ are the most important physical variables in this problem that can be interpreted as follows:

$$
\begin{aligned}
C_{f} & =\frac{\tau_{w}}{\rho_{f}\left(u_{e}\right)^{2}}, \\
N u_{x} & =\frac{x q_{w}}{k_{f}\left(T_{\infty}-T_{m}\right)} .
\end{aligned}
$$

Here, the symbol $\tau_{w}$ is shear stress of the stretching surface and $q_{w}$ is the heat flux, which is described as follows:

$$
\begin{gathered}
\tau_{w}=\mu_{h n f}\left(\frac{\partial u}{\partial y}\right)_{y=0}, \\
q_{w}=-k_{h n f}\left(\frac{\partial T}{\partial y}\right)_{y=0} .
\end{gathered}
$$

Substituting equation (13) into equation (12), we get

$$
\begin{gathered}
C_{f}=\frac{\mu_{h n f}}{\rho_{f}\left(u_{e}\right)^{2}}\left(\frac{\partial u}{\partial y}\right)_{y=0}, \\
N u_{x}=-\frac{x k_{h n f}}{k_{f}\left(T_{\infty}-T_{m}\right)}\left(\frac{\partial T}{\partial y}\right)_{y=0} .
\end{gathered}
$$

Using equations (7) and (14), we obtained

$$
\begin{aligned}
R e_{x}^{1 / 2} C_{f} & =\frac{\mu_{h n f}}{\mu_{f}} f^{\prime \prime}(0), \\
R e_{x}^{1 / 2} N u_{x} & =-\frac{k_{h n f}}{k_{f}} \theta^{\prime}(0) .
\end{aligned}
$$

Here, $R e_{x}=u_{e} x / v_{f}$ is the local Reynolds number.

\section{HAM Solution}

Optimal method is used for the solution procedure. The nonlinear ODEs (8) and (9) with boundary constraint (10) are solved through HAM. Mathematica program is accomplished for this process. The basic derivations of the modeled equations through HAM are detailed below.

$$
\begin{aligned}
\widehat{f}(\eta) & =1-e^{-\eta}, \\
\widehat{\Phi}(\eta) & =e^{-\eta}, \\
\widehat{\theta}(\eta) & =e^{-\eta}, \\
L_{\widehat{f}}(\widehat{f}) & =\widehat{f}^{\prime \prime \prime}, \\
L_{\widehat{\theta}}(\widehat{\theta}) & =\widehat{\theta}^{\prime \prime} .
\end{aligned}
$$

Linear operators $L_{\widehat{f}}$ and $L_{\widehat{\theta}}$ are signified as follows:

$$
\begin{aligned}
L_{\widehat{f}}\left(e_{1}+e_{2} \eta+e_{3} \eta^{2}\right) & =0, \\
L_{\widehat{\theta}}\left(e_{4}+e_{5} \eta\right) & =0 .
\end{aligned}
$$

The consistent nonlinear operator is appropriately chosen as $N_{\widehat{f}}$ and $N_{\widehat{\theta}}$ and recognized in system:

$$
N_{\widehat{f}}[\widehat{f}(\zeta ; \eta)]=\frac{\mu_{h n f}}{\mu_{f}} \widehat{f}_{\eta \eta \eta}+\widehat{f} \widehat{f}_{\eta \eta}-\widehat{f}_{\eta}^{2}+1
$$

$$
\begin{aligned}
& +\frac{\sigma_{h n f} / \sigma_{f}}{\rho_{h n f} / \rho_{f}} M\left(E-\left(1-\widehat{f}_{\eta}\right)\right), \\
N_{\hat{\theta}}[\widehat{f}(\zeta ; \eta), \widehat{\theta}(\zeta ; \eta)]= & \frac{1}{\operatorname{Pr}} \frac{k_{h n f} / k_{f}}{\left(\rho C_{p}\right)_{h n f} /\left(\rho C_{p}\right)_{f}} \widehat{\theta}_{\eta \eta} \\
& +\widehat{f} \widehat{\theta}_{\eta}+\frac{\sigma_{h n f} / \sigma_{f}}{\left(\rho C_{p}\right)_{h n f} / \rho_{f}} M E c\left(\widehat{f}_{\eta}-E\right) \\
& +\frac{\left(\rho C_{p}\right)_{f}}{\left(\rho C_{p}\right)_{h n f}} Q \widehat{\theta} .
\end{aligned}
$$

For equations (8) and (9), the $0^{\text {th }}$-order system is written as follows:

$$
\begin{aligned}
(1-\zeta) L_{\widehat{f}} & {\left[\widehat{f}(\zeta ; \eta)-\widehat{f}_{0}(\eta)\right]=p \hbar_{\widehat{f}} N_{\widehat{f}}[\widehat{f}(\zeta ; \eta)], } \\
(1-\zeta) L_{\hat{\theta}}\left[\widehat{\theta}(\zeta ; \eta)-\widehat{\theta}_{0}(\eta)\right] & =p \hbar_{\hat{\theta}} N_{\widehat{\theta}}[\widehat{f}(\zeta ; \eta), \widehat{\theta}(\zeta ; \eta)] .
\end{aligned}
$$

BCs are as follows:

$$
\begin{aligned}
& \left.\operatorname{Pr} \frac{\rho_{h n f}}{\rho_{f}} \widehat{f}(\zeta ; \eta)\right|_{\eta=0}+\left.M \frac{k_{h n f}}{k_{f}} \frac{\partial \widehat{\theta}(\zeta ; \eta)}{\partial \eta}\right|_{\eta=0}=0, \\
& \widehat{f}(0)=\lambda+\left.\alpha \frac{\partial^{2} \widehat{f}(\zeta ; \eta)}{\partial \eta^{2}}\right|_{\eta=0}+\left.\beta \frac{\partial^{2} \widehat{f}(\zeta ; \eta)}{\partial \eta^{2}}\right|_{\eta=0},\left.\widehat{\theta}(\zeta ; \eta)\right|_{\eta=0}=0 \\
& \left.\widehat{f}(\zeta ; \eta)\right|_{\eta=\infty} \longrightarrow 1,\left.\hat{\theta}(\zeta ; \eta)\right|_{\eta=\infty} \longrightarrow 1, \text { as } \eta \longrightarrow \infty \text {. }
\end{aligned}
$$

The embedded constraint $\zeta \in[0,1]$ is utilized to control the solution convergence $\hbar_{-}$and $\hbar_{-}$, when $\zeta=0$ and $\zeta=1$, and then we have the following: 


$$
\begin{gathered}
\widehat{f}(1 ; \eta)=\widehat{f}(\eta), \\
\hat{\theta}(1 ; \eta)=\widehat{\theta}(\eta) .
\end{gathered}
$$

For $\zeta=0$, expand $\hat{f}(\zeta ; \eta)$ and $\widehat{\theta}(\zeta ; \eta)$ through Taylor's expansion:

$$
\begin{gathered}
\hat{f}(\zeta ; \eta)=\widehat{f}_{0}(\eta)+\sum_{n=1}^{\infty} \widehat{f}_{n}(\eta) \zeta^{n} \\
\widehat{\theta}(\zeta ; \eta)=\widehat{\theta}_{0}(\eta)+\sum_{n=1}^{\infty} \widehat{\theta}_{n}(\eta) \zeta^{n} \\
\hat{f}_{n}(\eta)=\left.\frac{1}{n !} \frac{\partial \widehat{f}(\zeta ; \eta)}{\partial \eta}\right|_{p=0}, \\
\widehat{\theta}_{n}(\eta)=\left.\frac{1}{n !} \frac{\partial \hat{\theta}(\zeta ; \eta)}{\partial \eta}\right|_{p=0} .
\end{gathered}
$$

BCs are as follows:

$$
\begin{array}{r}
\operatorname{Pr} \frac{\rho_{h n f}}{\rho_{f}} \widehat{f}(0)+M \frac{k_{h n f}}{k_{f}} \widehat{\theta}^{\prime}(0)=0, \\
\hat{f}(0)=\lambda+\alpha \hat{f}^{\prime \prime}(0)+\beta \hat{f}^{\prime \prime}(0), \widehat{\theta}(0)=0, \\
\hat{f}^{\prime}(\eta) \longrightarrow 1, \hat{\theta}(\eta) \longrightarrow 1, \text { as } \eta \longrightarrow \infty
\end{array}
$$

Now,

$$
\begin{aligned}
\mathfrak{R}_{n}^{\widehat{f}}(\eta)= & \frac{\mu_{h n f}}{\mu_{f}} \widehat{f}_{n-1}^{\prime \prime \prime}+\sum_{j=0}^{w-1} \widehat{f}_{w-1-j} \widehat{f}_{j}^{\prime \prime}-\widehat{f}_{n-1}^{\prime 2}+1 \\
& +\frac{\sigma_{h n f} / \sigma_{f}}{\rho_{h n f} / \rho_{f}} M\left(E-\left(1-\widehat{f}_{n-1}^{\prime}\right)\right), \\
\mathfrak{R}_{n}^{\widehat{\theta}}(\eta)= & \frac{1}{\operatorname{Pr}} \frac{k_{h n f} / k_{f}}{\left(\rho C_{p}\right)_{h n f} /\left(\rho C_{p}\right)_{f}} \hat{\theta}_{n-1}^{\prime \prime}+\sum_{j=0}^{w-1} \widehat{f}_{w-1-j} \widehat{\theta}_{j}^{\prime} \\
& +\frac{\sigma_{h n f} / \sigma_{f}}{\left(\rho C_{p}\right)_{h n f} / \rho_{f}} M E c\left(\hat{f}_{n-1}^{\prime}-E\right)+\frac{\left(\rho C_{p}\right)_{f}}{\left(\rho C_{p}\right)_{h n f}} Q \widehat{\theta}_{n-1} .
\end{aligned}
$$

$$
\chi_{n}=\left\{\begin{array}{ll}
1, & \text { if } n>1 \\
0, & \text { if } n \leq 1
\end{array} .\right.
$$

\section{Result and Discussion}

The purpose of this section is to go through the physical factors of figures and tables, as well as to explain the true process behind the flow and temperature variations caused by physical variables $M, Q, \beta, \phi_{1}=\phi_{2}$, Ec, and Pr. A set of nonlinear ODEs (8) and (9) along with boundary constraints (10) are solved analytically using semianalytical techniques HAM in Mathematica software. The computed numerical results of $f^{\prime}(\eta)$ and $\theta(\eta)$ are achieved for different values of emerging parameters involved in the equations, like velocity slip parameter, magnetic field parameter, electric field parameter, volume fraction parameter, Eckert number, and Prandtl number. Graphical representation of physical flow model is shown in Figure 1 while graphical solution for velocity and temperature gradient is discussed in Figures 2-9. The velocity graphs for different values of $M, \beta$, and $E$ are shown in Figures 2-4. It is seen from Figure 2 that $f^{\prime}(\eta)$ decreased for increasing the values of $M$ with other parameters is fixed. It is obvious that the magnetic field depends on Lorentz force, which is stronger for a larger magnetic field. Therefore, velocity profile declines with more magnetic field. The effect of slip parameter on $f^{\prime}(\eta)$ is depicted in Figure 3. As we decrease the values of slip parameter as a result velocity profiles increase. Figure 4 shows that when the value of $E$ increases velocity profile of hybrid nanofluids improves significantly. It is the fact that the Lorentz force increasing as a result of electric field acts as an accelerating force that reduces the frictional resistance which causes to change the streamlines far from the linear stretching sheet.

Temperature graphs for different values of emerging parameters $M, E, E c, \operatorname{Pr}$, and $\phi_{1}=\phi_{2}$ are shown in Figures 5-9. Figure 5 indicates a comparative analysis of $\theta(\eta)$ for $\left(\mathrm{Al}_{2} \mathrm{O}_{3}-\mathrm{Cu}\right) / \mathrm{H}_{2} \mathrm{O}$ against different values of $M$. It is observed that temperature gradient rises with increasing values of $M$. Physically, this is due to the external magnetic field's retarding behavior, which generates an opposite Lorentz force, which suppresses momentum transfer and improves the thermal boundary layer's viscosity.

The impact of electric field parameter on $\theta(\eta)$ is shown in Figure 6. The temperature profile enhances with rise in the values of electric field. Due to Lorentz effect, the electric field accelerates fluid temperature and thermal boundary layers.

The graphical result of temperature gradient for $\left(\mathrm{Al}_{2} \mathrm{O}_{3}-\mathrm{Cu}\right) / \mathrm{H}_{2} \mathrm{O}$ against Eckert number (Ec) when $\phi_{1}=\phi_{2}=0.03, \operatorname{Pr}=6.4, E=0.6$, and $M=0.8$ is present in Figure 7. It is seen that the values of Ec enhance. Physically, Eckert number is the ratio of kinetic energy to the specific enthalpy difference between wall and fluid. Therefore, an increase in Eckert number causes the transformation of kinetic energy into internal energy by work that is done against the viscous fluid stresses. Due to this, increasing Ec enhances the temperature of the fluid. The effect of $\mathrm{Pr}$ on temperature field is shown in Figure 8. This happens basically because high values of Prandtl number relate to weak thermal diffusivity, which upshots in a thinner thermal boundary layer. As a matter of fact, intensification in the Prandtl number infers an upsurge in fluid viscosity, which consecutively causes deterioration in temperature distribution. Hence, $\operatorname{Pr}$ can be used to upturn the rate of cooling in flows. The influence of $\phi_{1}$ and $\phi_{2}$ (volume fractions of $\mathrm{Al}_{2} \mathrm{O}_{3}+\mathrm{H}_{2} \mathrm{O}$ and $\mathrm{Cu}+\mathrm{H}_{2} \mathrm{O}$ hybrid nanoparticles, respectively) on $\theta(\eta)$ is depicted in Figure 9. For both types of nanoparticles, it is discovered that the fluid temperature rises as $\phi_{1}=\phi_{2}$ increases. The specific heat capacity of nanoliquid is physically reduced as the credit of $\phi_{1}=\phi_{2}$ increases. Furthermore, it boosts nanoliquid thermal expansion; therefore, temperature field rises with the rise of $\phi_{1}=\phi_{2}$. 


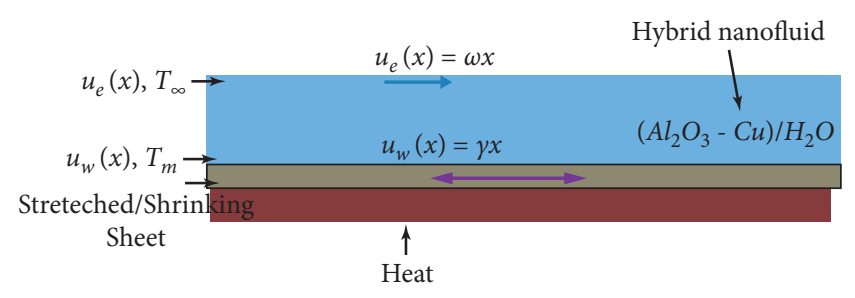

Figure 1: Graphical representation to illustrate the overall idea of the model.

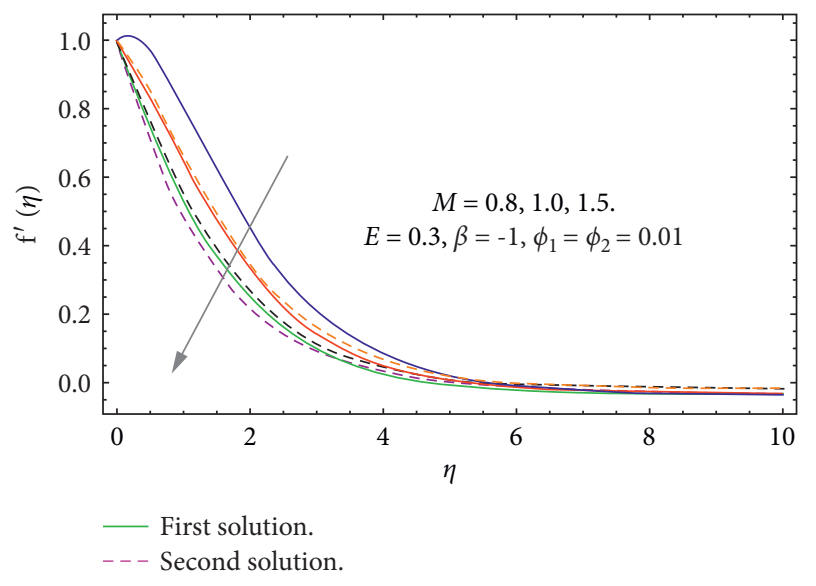

Figure 2: Velocity gradient corresponds to different values of $M$.

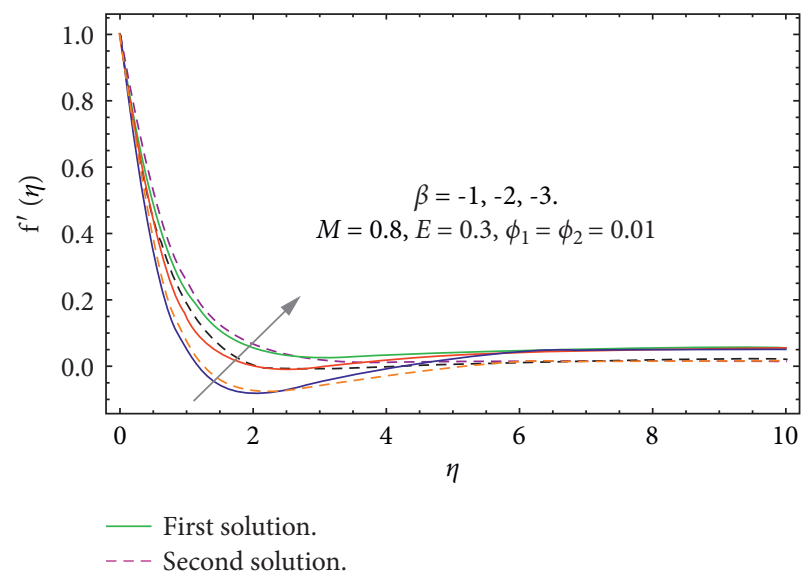

FIgURE 3: Velocity gradient corresponds to different values of $\beta$.

Thermophysical characteristics of nanofluid and hybrid nanofluid are defined in Table 1 , while $(\mathrm{Cu})$ thermophysical characteristics along with $\left(\mathrm{Al}_{2} \mathrm{O}_{3}\right)$ and $\left(\mathrm{H}_{2} \mathrm{O}\right)$ are given in Table 2. The numerical result of skin friction coefficient for different embedded parameters is presented in Table 3. We illustrate that the values of skin friction enhanced for more magnetic field and volume fraction. In fact, magnetic field produces more resistive type force against the fluid flow, and hybrid nanofluids have a higher density than ordinary fluids. Further, $\mathrm{C}_{f}$ declines, when values of $E$ enhanced. It is seen that $C_{f}$ also decreased as we decreased values of $\beta$. The numerical solution of local Nusselt number against various

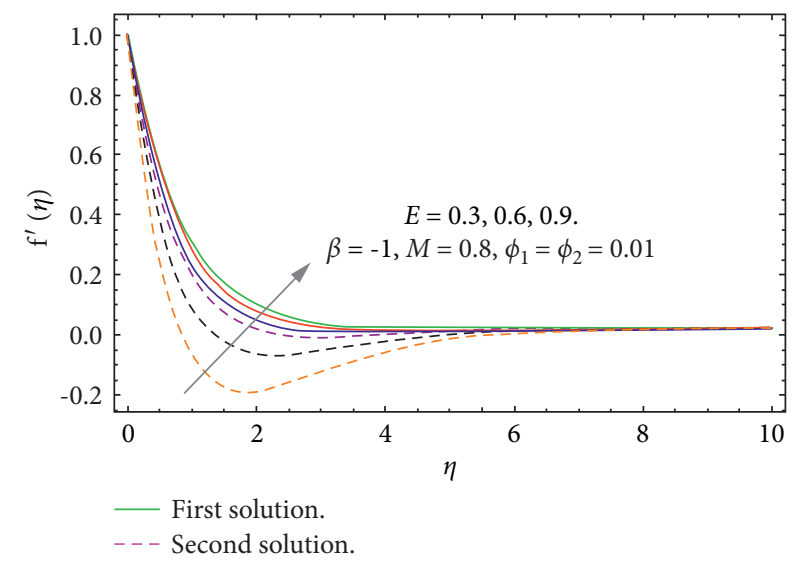

FIgURE 4: Velocity gradient corresponds to different values of $E$.

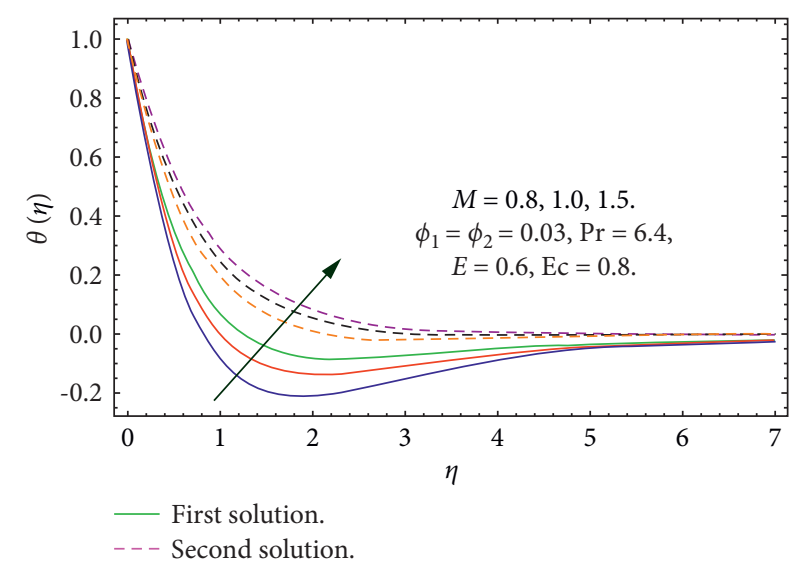

FIGURE 5: Temperature gradient corresponds to different values of $M$.

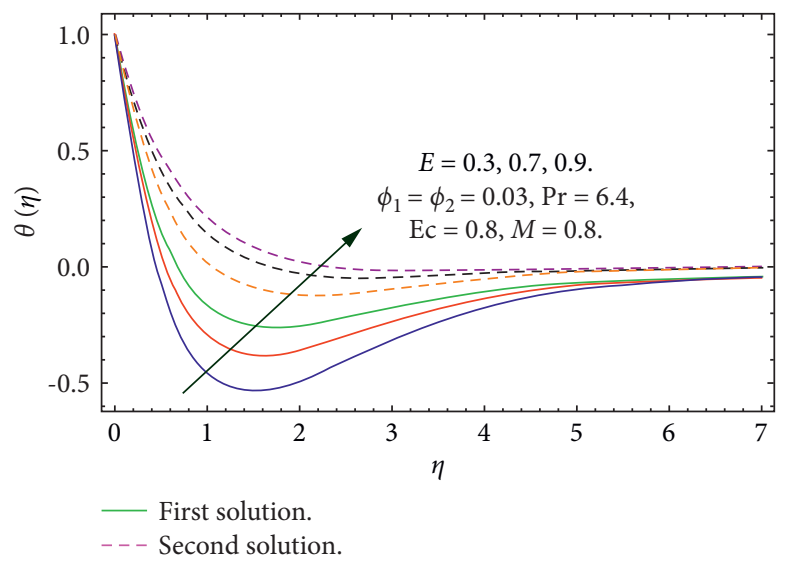

FIgURE 6: Temperature gradient corresponds to different values of E.

values of $M, Q, E, \mathrm{Ec}, \mathrm{Pr}$, and $\phi_{1}=\phi_{2}$ is shown in Table 4 . Increasing values of $M, Q, E, E c$, and $\phi_{1}=\phi_{2}$ boots up the Nusselt number while decreased for more values of Pr. Comparison between HAM and NDSolve solution for $f(\eta)$, $f^{\prime}(\eta)$, and $\theta(\eta)$ is shown in Table 5. Hybrid nanofluid has 


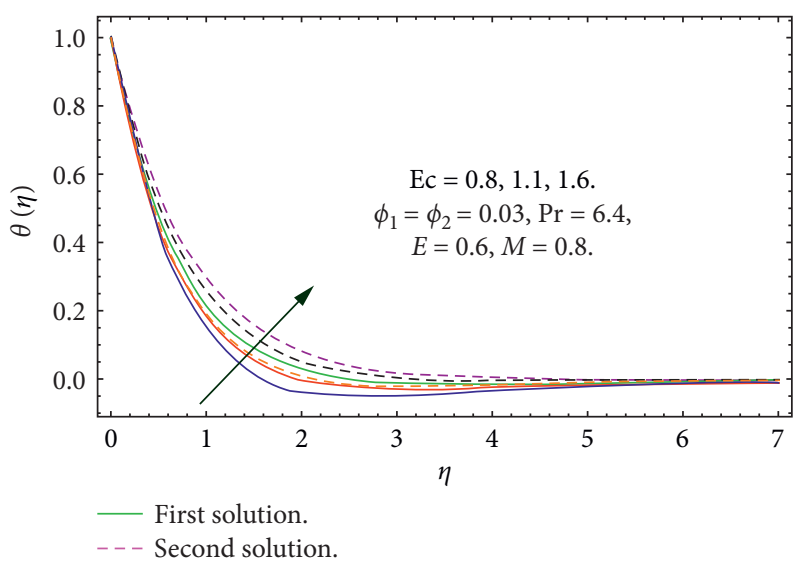

Figure 7: Temperature gradient corresponds to different values of Ec.

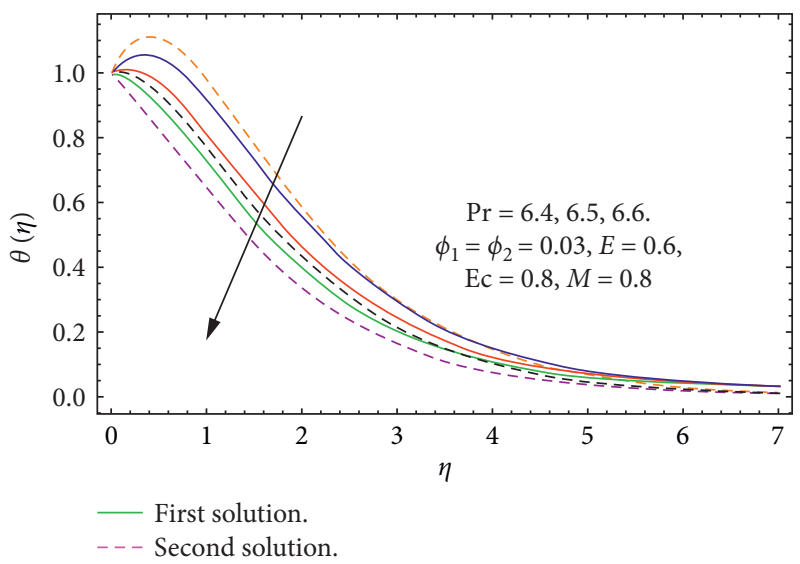

Figure 8: Temperature gradient corresponds to different values of Pr.

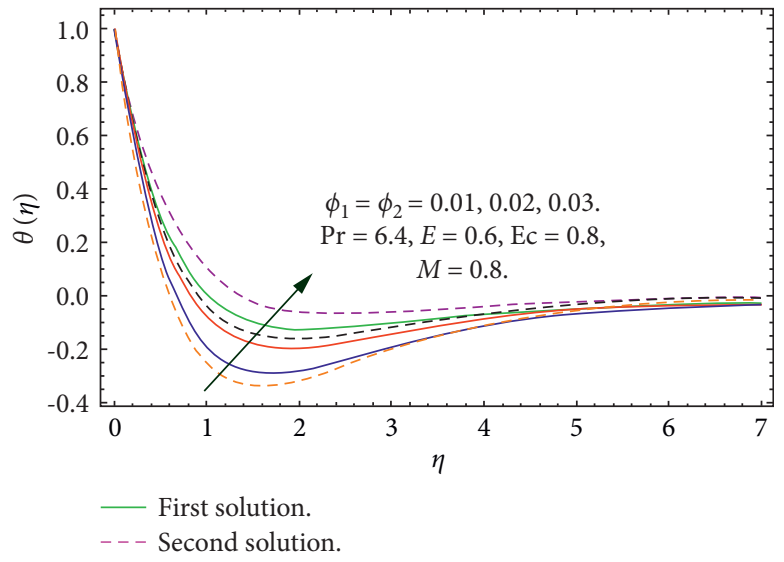

Figure 9: Temperature gradient corresponds to different values of $\phi_{1}=\phi_{2}$. 


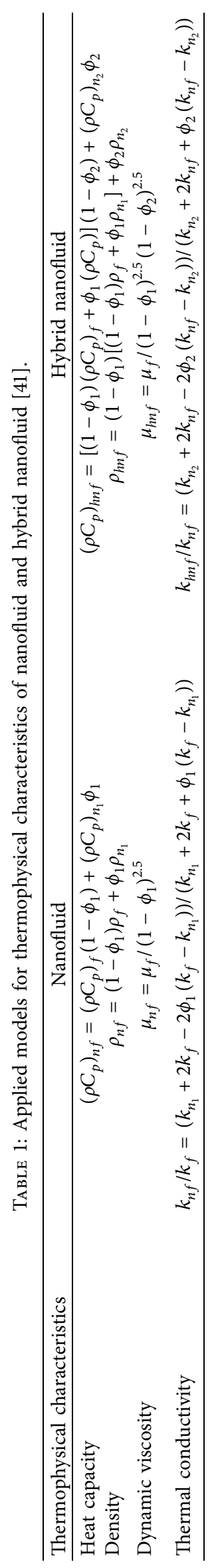


TABLE 2: $\mathrm{Cu}$ thermophysical characteristics along with $\mathrm{Al}_{2} \mathrm{O}_{3}$ and $\mathrm{H}_{2} \mathrm{O}$ [42].

\begin{tabular}{lccc}
\hline Thermophysical characteristics & $\mathrm{Al}_{2} \mathrm{O}_{3}$ & $\mathrm{Cu}$ & $\mathrm{H}_{2} \mathrm{O}$ \\
\hline$\rho\left(\mathrm{kg} / \mathrm{m}^{3}\right)$ & 3970 & 8933 & 997.1 \\
$C_{p}(\mathrm{~J} / \mathrm{kgK})$ & 765 & 385 & 4179 \\
$\mathrm{k}(\mathrm{W} / \mathrm{m} K)$ & 40 & 400 & 0.613 \\
$\beta_{1} \times 10^{5}(1 / K)$ & 0.85 & $\mathrm{I} .67$ & 21 \\
\hline
\end{tabular}

TABLE 3: Numerical solution of $R e_{x}^{1 / 2} C_{f}=\mu_{h n f} / \mu_{f} f^{\prime \prime}(0)$ for various values of $M, E, \beta$, and $\phi_{1}=\phi_{2}$.

\begin{tabular}{ccccc}
\hline$M$ & $E$ & $\beta$ & $\phi_{1}=\phi_{2}$ & \multicolumn{2}{c}{$R e_{x}^{1 / 2} C_{f}=\mu_{h n f} / \mu_{f} f^{\prime \prime}(0)$} \\
Second solution
\end{tabular}

TABLE 4: Numerical solution of $R e_{x}^{-1 / 2} N u_{x}=-k_{h n f} / k_{f} \theta^{\prime}(0)$ for various values of $M, Q, \operatorname{Pr}, E$, Ec, and $\phi_{1}=\phi_{2}$.

\begin{tabular}{ccccccc}
\hline$M$ & $Q$ & Pr & $E$ & Ec & $\phi_{1}=\phi_{2}$ & \multicolumn{2}{c}{$R e_{x}^{1 / 2} N u_{x}=-k_{h n f} / k_{f} \theta^{\prime}(0)$} \\
Second solution
\end{tabular}

TABLE 5: Comparison between HAM and NDSolve solution.

\begin{tabular}{lcccccc}
\hline & $f(\eta)$ & & \multicolumn{2}{c}{$f^{\prime}(\eta)$} & & $\theta(\eta)$ \\
& HAM & NDSolve & HAM & NDSolve & HAM & 0.254 \\
0 & 0 & 0 & 0.045639405 & 0.045639394 & 0.254 \\
0.5 & 0.020450172 & 0.020450164 & 0.097702304 & 0.097702295 & 0.208120116 & 0.208120102 \\
1.0 & 0.021416272 & 0.021416265 & 0.105158029 & 0.105158016 & 0.209405201 & 0.209405182 \\
\hline
\end{tabular}


TABLE 5: Continued.

\begin{tabular}{|c|c|c|c|c|c|c|}
\hline \multirow[b]{2}{*}{$\eta$} & \multicolumn{2}{|c|}{$f(\eta)$} & \multicolumn{2}{|c|}{$f^{\prime}(\eta)$} & \multicolumn{2}{|c|}{$\theta(\eta)$} \\
\hline & HAM & NDSolve & HAM & NDSolve & HAM & NDSolve \\
\hline 1.5 & 0.021750481 & 0.021750471 & 0.107420204 & 0.107420192 & 0.217165026 & 0.217165007 \\
\hline 2.0 & 0.022067245 & 0.022067232 & 0.109330074 & 0.109330058 & 0.218410128 & 0.218410115 \\
\hline 2.5 & 0.025150151 & 0.025150145 & 0.116018154 & 0.116018145 & 0.219040166 & 0.219040149 \\
\hline 3.0 & 0.026948161 & 0.026948152 & 0.117341044 & 0.117341032 & 0.220512221 & 0.220512213 \\
\hline 3.5 & 0.028320341 & 0.028320333 & 0.119318774 & 0.119318749 & 0.222096096 & 0.222096057 \\
\hline 4.0 & 0.029670405 & 0.029670385 & 0.124631244 & 0.124631225 & 0.238425621 & 0.238425611 \\
\hline 4.5 & 0.105450161 & 0.105450152 & 0.140581204 & 0.140581175 & 0.248059096 & 0.248059067 \\
\hline 5.0 & 0.108250325 & 0.108250318 & 0.142054024 & 0.142054015 & 0.257521616 & 0.257521599 \\
\hline 5.5 & 0.117261209 & 0.117261192 & 0.143486343 & 0.143486315 & 0.258049316 & 0.258049297 \\
\hline 6.0 & 0.122631101 & 0.122631092 & 0.145783104 & 0.145783086 & 0.266089225 & 0.266089201 \\
\hline 6.5 & 0.134707161 & 0.134707148 & 0.146435034 & 0.146435025 & 0.270104196 & 0.270104147 \\
\hline 7.0 & 0.135707551 & 0.135707549 & 0.147049144 & 0.147049127 & 0.295086326 & 0.295086301 \\
\hline 7.5 & 0.142720621 & 0.142720602 & 0.148220494 & 0.148220413 & 0.298138418 & 0.298138402 \\
\hline
\end{tabular}

been found to be more efficient in increasing heat absorption or generation rates as compared to conventional fluids.

$$
\begin{aligned}
\phi_{1} & =0.01, \\
\phi_{2} & =0.01, \\
E & =0.3, \\
E c & =1.1, \\
\operatorname{Pr} & =6.4, \\
M & =0.8, \\
Q & =0.5 .
\end{aligned}
$$

\section{Conclusion}

An analysis of the steady 2D boundary layer MHD stagnation point flow of hybrid nanofluid over a stretching/ shrinking sheet is examined in this study. Electric field, second-order slip, and melting heat transfer are considered. The boundary layer governing equations are transformed to nonlinear ordinary differential equations using similarity transformations and then solved by HAM. Influence of several variables on velocity and temperature is scrutinized. Numerical outcomes of velocity gradient and heat transfer rates against various parameters are deliberated. Also, comparison between HAM and NDSolve solution is computed. Some significant aspects throughout this report skew our judgment on the following remarks:

(i) Increasing values of electric field enhanced $f^{\prime}(\eta)$, while more magnetic field decreased $f^{\prime}(\eta)$.

(ii) As we decrease the values of slip parameter as a result $f^{\prime}(\eta)$ boots up while $C_{f}$ declines.

(iii) More values of $M, Q, E, E c$, and $\phi_{1}=\phi_{2}$ enhanced temperature profile, while high Prandtl number $\mathrm{Pr}$ declines $\theta(\eta)$.

(iv) Skin friction boots up for more magnetic field and volume frictions while decreases as we increase electric field parameter. (v) High values of $M, Q, E, E c$, and $\phi_{1}=\phi_{2}$ enhanced the local Nusselt number.

(vi) High estimation of Prandtl number reduces $N u_{x}$.

(vii) In comparison with conventional fluids, hybrid nanofluids are quick agents for thermal analysis study, according to the findings.

(viii) The current findings are limited to the use of $(\mathrm{Cu})$ and $\left(\mathrm{Al}_{2} \mathrm{O}_{3}\right)$ nanoparticles in combination. Other researchers, on the additional hand, may expand the study to include other hybrid nanofluids or physical factors in order to obtain the desired result.

\section{Notation}

$u$ : $\quad$ Velocity term with respect to $x$-axis

$v$ : $\quad$ Velocity term with respect to $y$-axis

$u_{e}: \quad$ Free stream velocity $\left(\mathrm{ms}^{-1}\right)$

$u_{w}: \quad$ Surface velocity $\left(\mathrm{ms}^{-1}\right)$

$f(\eta)$ : Dimensionless stream function

$L: \quad$ Latent heat of the fluid $\left(\mathrm{Jkg}^{-1}\right)$

$C_{p}$ : Specific heat at constant pressure $\left(\mathrm{Jkg}^{-1} \mathrm{~K}^{-1}\right)$

$k: \quad$ Thermal conductivity $\left(\mathrm{Wm}^{-1} \mathrm{~K}^{-1}\right)$

$c_{s}: \quad$ Heat capacity of surface $\left(\mathrm{kgm}^{-1} \mathrm{~s}^{-2}\right)$

Pr: Prandtl number

$R e_{x}$ : Local Reynolds number

$N u_{x}$ : Local Nusselt number

Ec: $\quad$ Eckert number

M: $\quad$ Magnetic parameter

E: $\quad$ Electric parameter

Q: $\quad$ Heat absorption parameter

$\beta$ : $\quad$ Velocity slip parameter

$\omega, \gamma$ : Constant

$T: \quad$ Temperature of the fluid $(\mathrm{K})$

$T_{m}: \quad$ Surface temperature (K)

$\rho: \quad$ Density of fluid $\left(\mathrm{kgm}^{-3}\right)$

$n_{1}$ : Solid component of $\left(\mathrm{Al}_{2} \mathrm{O}_{3}\right)$

$\mu$ : $\quad$ Dynamic viscosity of fluid $\left(\mathrm{kgm}^{-1} \mathrm{~s}^{-1}\right)$

$\theta: \quad$ Dimensionless temperature

$\rho C_{p}$ : Heat capacity of fluid $\left(\mathrm{JK}^{-1} \mathrm{~m}^{-3}\right)$

$v: \quad$ Kinematic viscosity of fluid $\left(\mathrm{m}^{2} \mathrm{~s}^{-1}\right)$ 


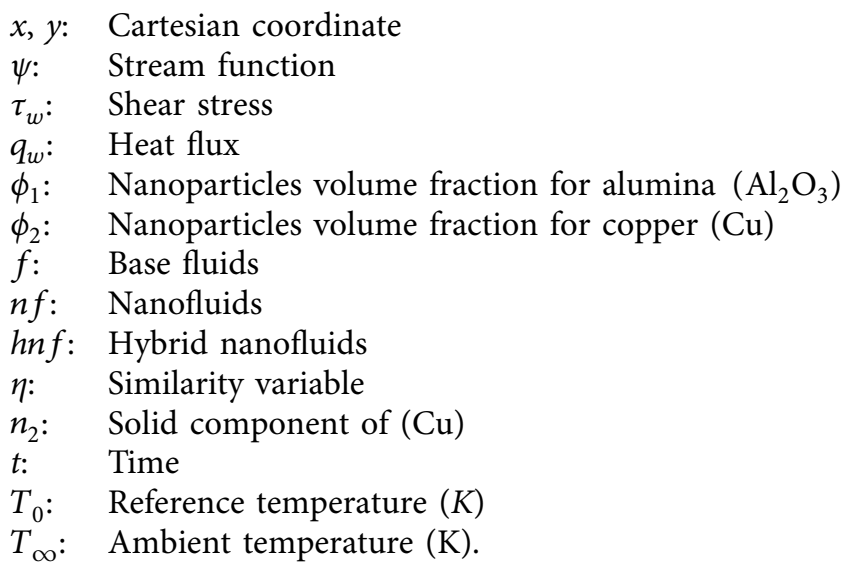

\section{Data Availability}

No data were used to support this study.

\section{Conflicts of Interest}

The authors declare that they have no conflicts of interest.

\section{References}

[1] F. M. Alharbi, M. Naeem, M. Zubair, M. Jawad, W. U. Jan, and R. Jan, "Bioconvection due to gyrotactic microorganisms in couple stress hybrid nanofluid laminar mixed convection incompressible flow with magnetic nanoparticles and chemical reaction as carrier for targeted drug delivery through porous stretching sheet," Molecules, vol. 26, no. 13, Article ID 3954, 2021.

[2] S. M. Boulaaras, A. Choucha, M. Abdalla, K. Rajagopal, and S. A. Idris, "Blow-up of solutions for a coupled nonlinear viscoelastic equation with degenerate damping terms: without Kirchhoff term," Complexity, vol. 2021, no. 1, 9 pages, Article ID 6820219, 2021.

[3] S. Manaa, S. Boulaaras, H. Benseridi, M. Dilmi, and S. Alodhaibi, "Analysis for flow of an incompressible brinkman-type fluid in thin medium with friction," Journal of Function Spaces, vol. 2021, Article ID 5112840, 8 pages, 2021.

[4] H. M. Srivastava, R. Jan, A. Jan, W. Deebani, and M. Shutaywi, "Fractional-calculus analysis of the transmission dynamics of the dengue infection," Chaos: An Interdisciplinary Journal of Nonlinear Science, vol. 31, no. 5, Article ID 053130, 2021.

[5] S. M. Boulaaras, A. Choucha, A. Zara, M. Abdalla, and B. B. Cheri, "Global existence and decay estimates of energy of solutions for a new class of-Laplacian heat equations with logarithmic nonlinearity," Journal of Function Spaces, vol. 2021, Article ID 5558818, 11 pages, 2021.

[6] S. K. Verma, A. K. Tiwari, S. Tiwari, and D. S. Chauhan, "Performance analysis of hybrid nanofluids in flat plate solar collector as an advanced working fluid," Solar Energy, vol. 167, pp. 231-241, 2018.

[7] N. Chen, H. Ma, Y. Li et al., "Complementary optical absorption and enhanced solar thermal conversion of $\mathrm{CuO}$ ATO nanofluids," Solar Energy Materials and Solar Cells, vol. 162, pp. 83-92, 2017.

[8] J. Zeng and Y. Xuan, "Enhanced solar thermal conversion and thermal conduction of MWCNT-SiO2/Ag binary nanofluids," Applied Energy, vol. 212, pp. 809-819, 2018.
[9] Y. Xuan, H. Duan, and Q. Li, “Enhancement of solar energy absorption using a plasmonic nanofluid based on $\mathrm{TiO} 2 / \mathrm{Ag}$ composite nanoparticles," RSC Advances, vol. 4, no. 31, pp. 16206-16213, 2014.

[10] S.-S. Bi, L. Shi, and L.-L. Zhang, "Application of nanoparticles in domestic refrigerators," Applied Thermal Engineering, vol. 28, no. 14-15, pp. 1834-1843, 2008.

[11] M. S. Ahmed and A. M. Elsaid, "Effect of hybrid and single nanofluids on the performance characteristics of chilled water air conditioning system," Applied Thermal Engineering, vol. 163, Article ID 114398, 2019.

[12] D. Madhesh and S. Kalaiselvam, "Experimental study on heat transfer and rheological characteristics of hybrid nanofluids for cooling applications," Journal of Experimental Nanoscience, vol. 10, no. 15, pp. 1194-1213, 2015.

[13] H. R. Allahyar, F. Hormozi, and B. ZareNezhad, "Experimental investigation on the thermal performance of a coiled heat exchanger using a new hybrid nanofluid," Experimental Thermal and Fluid Science, vol. 76, pp. 324-329, 2016.

[14] M. K. A. Ali, H. Xianjun, L. Mai, C. Bicheng, R. F. Turkson, and C. Qingping, "Reducing frictional power losses and improving the scuffing resistance in automotive engines using hybrid nanomaterials as nano-lubricant additives," Wear, vol. 364-365, pp. 270-281, 2016.

[15] N. A. C. Sidik, M. N. A. W. M. Yazid, and R. Mamat, "A review on the application of nanofluids in vehicle engine cooling system," International Communications in Heat and Mass Transfer, vol. 68, pp. 85-90, 2015.

[16] C. Choi, H. S. Yoo, and J. M. Oh, "Preparation and heat transfer properties of nanoparticle-in-transformer oil dispersions as advanced energy-efficient coolants," Current Applied Physics, vol. 8, no. 6, pp. 710-712, 2008.

[17] J. Buongiorno and L.-W Hu, "Innovative technologies: twophase heat transfer in water-based nanofluids for nuclear applications final report," Massachusetts Institute of Technology, Cambridge, MA, USA, No. DOE/ID/14765-8, 2009.

[18] S. M. Mousavizadeh, G. R. Ansarifar, and M. Talebi, "Assessment of the TiO2/water nanofluid effects on heat transfer characteristics in VVER-1000 nuclear reactor using CFD modeling," Nuclear Engineering and Technology, vol. 47, no. 7, pp. 814-826, 2015.

[19] B. Godin, J. H. Sakamoto, R. E. Serda, A. Grattoni, A. Bouamrani, and M. Ferrari, "Emerging applications of nanomedicine for the diagnosis and treatment of cardiovascular diseases," Trends in Pharmacological Sciences, vol. 31, no. 5, pp. 199-205, 2010.

[20] V. Sridhara, B. S. Gowrishankar, Snehalatha, and L. N. Satapathy, "Nanofluids-a new promising fluid for cooling," Transactions - Indian Ceramic Society, vol. 68, no. 1, pp. 1-17, 2009.

[21] C. Kleinstreuer, J. Li, and J. Koo, "Microfluidics of nano-drug delivery," International Journal of Heat and Mass Transfer, vol. 51, no. 23-24, pp. 5590-5597, 2008.

[22] D. Bica, L. Vékás, M. V. Avdeev et al., "Sterically stabilized water based magnetic fluids: synthesis, structure and properties," Journal of Magnetism and Magnetic Materials, vol. 311, no. 1, pp. 17-21, 2007.

[23] J.-F. Yan and J. Liu, "Nanocryosurgery and its mechanisms for enhancing freezing efficiency of tumor tissues," Nanomedicine: Nanotechnology, Biology and Medicine, vol. 4, no. 1, pp. 79-87, 2008.

[24] D. Mansoury, F. Ilami Doshmanziari, S. Rezaie, and M. M. Rashidi, "Effect of $\mathrm{Al} 2 \mathrm{O} 3 /$ water nanofluid on 
performance of parallel flow heat exchangers," Journal of Thermal Analysis and Calorimetry, vol. 135, no. 1, pp. 625643, 2019.

[25] N. M. S. Ghazali, K. Abdul Hamid, S. K. Soid, A. S. A. Aziz, and Z. Md Ali, "Stagnation point flow in nanofluids over a shrinking cylinder with slip effect and viscous dissipation," AIP Conference Proceedings, vol. 2266, no. 1, Article ID 50003, 2020.

[26] W. Alghamdi, A. Alsubie, P. Kumam, A. Saeed, and T. Gul, "MHD hybrid nanofluid flow comprising the medication through a blood artery," Scientific Reports, vol. 11, no. 1, pp. 1-13, 2021.

[27] M. Ijaz Khan and F. Alzahrani, "Entropy optimized magnetohydrodynamics Darcy-Forchheimer second order velocity slip flow of nanomaterials between two stretchable disks," Proceedings of the Institution of Mechanical Engineers Part C: Journal of Mechanical Engineering Science, vol. 234, no. 21, pp. 4190-4199, 2020.

[28] T. Gul, M. Bilal, W. Alghamdi, M. I. Asjad, and T. Abdeljawad, "Hybrid nanofluid flow within the conical gap between the cone and the surface of a rotating disk," Scientific Reports, vol. 11, no. 1, pp. 1-19, 2021.

[29] S. S. Ghadikolaei, M. Yassari, H. Sadeghi, K. Hosseinzadeh, and D. D. Ganji, "Investigation on thermophysical properties of Tio2- $\mathrm{Cu} / \mathrm{H} 2 \mathrm{O}$ hybrid nanofluid transport dependent on shape factor in MHD stagnation point flow," Powder Technology, vol. 322, pp. 428-438, 2017.

[30] T. Tayebi and A. J. Chamkha, "Free convection enhancement in an annulus between horizontal confocal elliptical cylinders using hybrid nanofluids," Numerical Heat Transfer, Part A: Applications, vol. 70, no. 10, pp. 1141-1156, 2016.

[31] I. Waini, A. Ishak, and I. Pop, "Hybrid nanofluid flow and heat transfer over a permeable biaxial stretching/shrinking sheet," International Journal of Numerical Methods for Heat and Fluid Flow, vol. 30, no. 7, pp. 3497-3513, 2019.

[32] T. Hayat, S. Nadeem, and A. U. Khan, "Rotating flow of Ag$\mathrm{CuO} / \mathrm{H} 2 \mathrm{O}$ hybrid nanofluid with radiation and partial slip boundary effects," The European Physical Journal E, vol. 41, no. 6, Article ID 75, 2018.

[33] M. Subhani and S. Nadeem, "Numerical analysis of micropolar hybrid nanofluid," Applied Nanoscience, vol. 9, no. 4, pp. 447-459, 2019.

[34] N. S. Khashi'ie, N. Md Arifin, R. Nazar, E. H. Hafidzuddin, N. Wahi, and I. Pop, "Magnetohydrodynamics (MHD) axisymmetric flow and heat transfer of a hybrid nanofluid past a radially permeable stretching/shrinking sheet with Joule heating," Chinese Journal of Physics, vol. 64, pp. 251-263, 2020.

[35] N. A. Zainal, R. Nazar, K. Naganthran, and I. Pop, "MHD mixed convection stagnation point flow of a hybrid nanofluid past a vertical flat plate with convective boundary condition," Chinese Journal of Physics, vol. 66, pp. 630-644, 2020.

[36] E. H. Aly and I. Pop, "MHD flow and heat transfer near stagnation point over a stretching/shrinking surface with partial slip and viscous dissipation: hybrid nanofluid versus nanofluid," Powder Technology, vol. 367, pp. 192-205, 2020.

[37] I. Waini, A. Ishak, and I. Pop, "Melting heat transfer of a hybrid nanofluid flow towards a stagnation point region with second-order slip," Proceedings of the Institution of $\mathrm{Me}$ chanical Engineers - Part E: Journal of Process Mechanical Engineering, vol. 235, no. 2, pp. 405-415, 2021.

[38] T. Walelign, E. Haile, T. Kebede, and G. Awgichew, "Heat and mass transfer in stagnation point flow of maxwell nanofluid towards a vertical stretching sheet with effect of induced magnetic field," Mathematical Problems in Engineering, vol. 2021, Article ID 6610099, 2021.

[39] L. Roberts, "On the melting of a semi-infinite body of ice placed in a hot stream of air," Journal of Fluid Mechanics, vol. 4 , no. 5, pp. 505-528, 1958.

[40] L. Wu, "A slip model for rarefied gas flows at arbitrary Knudsen number," Applied Physics Letters, vol. 93, no. 25, Article ID 253103, 2008.

[41] H. F. Oztop and E. Abu-Nada, "Numerical study of natural convection in partially heated rectangular enclosures filled with nanofluids," International Journal of Heat and Fluid Flow, vol. 29, no. 5, pp. 1326-1336, 2008.

[42] N. A. Zainal, R. Nazar, K. Naganthran, and I. Pop, "Unsteady stagnation point flow of hybrid nanofluid past a convectively heated stretching/shrinking sheet with velocity slip," Mathematics, vol. 8, no. 10, Article ID 1649, 2020. 